\title{
The Convergence of Manufacturing and Service Technologies: A Patent Analysis Approach
}

\author{
Youngjung Geum¹, Moon-Soo Kim², Yongtae Park ${ }^{1},{ }^{*}$ Sungjoo Lee ${ }^{3}$ \\ ${ }^{1}$ Seoul National University, Republic of Korea \\ ${ }^{2}$ Hankuk University of Foreign Studies (HUFS), Republic of Korea \\ ${ }^{3}$ Ajou University, Republic of Korea \\ *sungjoo@ajou.ac.kr
}

\begin{abstract}
Active technological convergence of manufacturing industries and service industries has been emerged as a core and essential phenomenon for recent business environment. Technology convergence has already been the basic force behind the both product innovation and service innovation, changing the ways in which firms interact with their customers. Despite the gravity, there has been limited approach to investigate the technological convergence of manufacturing technologies and service technologies from the empirical perspective. In response, this paper aims to investigate technological convergence between manufacturing technology and service technology using patent analysis. For this purpose, we define the service technology and manufacturing technology. Following on this, we analyze the USPC classification of those technologies to analyze the technological convergence. To investigate the dynamic change of convergence, 10-year-dyanamics are observed. As case studies, three industries which show high level of technological convergence of manufacturing and service - banking, healthcare, and education industries are selected and analyzed in detail.
\end{abstract}

Keywords: Technological convergence, manufacturing, service, technology, patent analysis

\section{Introduction}

Traditionally, technology has been a central axis for the manufacturing industry. Quite naturally, development and application of a certain technology used to be the scope of product innovation. However, it is recently argued that the application of technology is not simply resorted to the manufacturing industry, but extended to the service industry (Quinn et al., 1988; Quinn and Paquett, 1990; Kang, 2006). Rather, technology triggers the active convergence of products and services, which has been considered as a core and essential phenomenon for many firms to gain profit (Bore's et al., 2003). Technological convergence is behind this interesting phenomenon: manufacturing-service convergence. It has already been the basic force behind the both product and service innovation, changing the ways in which firms interact with their customers (Bitner, 2001; Auernhammer \& Stabe, 2002; Geum et al., 2011). Therefore, technology convergence occupies a substantial part of product-service convergence, enabling the active associations of two different industries. This phenomenon can be proven by many practical cases of current business environment: companies such as IBM, General Electric, and Xerox have been gaining profits from technology-originated services since the middle of 1990s, exemplifying a shift from the manufacturing-oriented industry to convergence industries (Martinez et al., 2010; Geum et al., 2011). Despite the importance of technological convergence in manufacturing industries and service industries, there has been a limited approach to investigate this phenomenon from the empirical perspective.

The lack of data on investigating the technological convergence being a major impediment, previous research has been resorted to the theoretical investigation of technological convergence, focusing on the discussion of current phenomena of technological convergence (Blackman, 1998; Bores et al., 2003; Stehrer \& Worz, 2003; Hacklin, 2008; Hacklin et al., 2009; Lee et al., 2010). Even though some empirical research has tried to investigate the technological convergence (Curran and Leker, 2009; Curran and Leker, 2011), these research have been limited to the manufacturing industries only, or industries with high technology such as information and communication technology (ICT) industry. Research on technological convergence between manufacturing technology and service technology still remains as void in the literature. However, given the substantial dynamics of manufacturing-service convergence, it is highly required to investigate the technological convergence between manufacturing and service. Addressing the limitation of previous research, our study aims to investigate the technological convergence between manufacturing technology and service technology using patent analysis. For this 
purpose, we first define the service technology and corresponding manufacturing technology. As an analysis method, we employ patent classification analysis which has been regarded as an imperative means to identify technological convergence and proximity (Tijssen, 1992; Karvonen \& Kässi, 2011; Geum et al, 2012). The remainder of this paper is organized as follows. The theoretical and methodological background is discussed in the Literature Review. Next, the research framework of this paper is suggested with overall process and detailed procedure. Next, the result of analysis is provided in the experiment section. Finally, contributions and limitations of this research are discussed in the conclusion.

\section{Literature Review}

Technological convergence: From the work of Rosenberg in 1963 (Rosenberg, 1963), technological convergence has been widely discussed in many literatures (Lee et al., 2010). Technological convergence is defined as the process by which different industries come to share similar technological bases (Rosenberg, 1963). It is prompted by the rise of some generic technologies that can be applied to a wealth of different products (Gambardella \& Torrisi, 1998). Many different areas have been involved in the technological convergence, such as information and communications technology (ICT), robotics, medical industry, education industry, and banking industry. Especially, digital convergence, driven by ICT industry, involves analog-digital integration, wired-wireless integration, voice-data integration, and service-device integration, which result in convergence of networks and telecom-broadcasting convergence. Previous research on technological convergence is mainly concerned with the theoretical and practical investigation of technological convergence, including an ex ante definition of convergence or in-depth explanation of current phenomena of technological convergence (Stehrer \& Worz, 2003; Hacklin, 2008; Hacklin et al., 2009; Lee et al., 2010). Extended from the theoretical investigation, some research have devoted to the managerial and policy implications which are incurred by the technological convergence (Blackman, 1998; Bores et al., 2003).

Patent analysis: Patents have long been used as a proxy measure for technological power (Grilliches, 1990). The basic method for patent analysis was the bibliometric analysis which simply counts the number of patents (Wartburg et al., 2005). Extended from the bibliometric analysis, some advanced techniques have been employed such as citation analysis and classification analysis. Patent citation analysis is based on the assumption that more frequently cited patents have higher technological power (Narin et al., 1987). Another important strength of citation analysis is to identify similarities between technologies (Lee et al., 2009). Since we can assume that cited patents are closely related to the original patents, patent citation can be considered as an important measure for technological convergence. Patent classification analysis is another important method to measure the similarity of two patents. Patent class refers to the way the examiners of a patent office arrange patent documents according to the technical features (Geum et al., 2012). Since the same document may be classified in several classes, the coclassification can be used to identify the relationships between technologies. To investigate the technological convergence, there have been a few studies to employ patent document. Since patent documents are an ample source for technical and commercial knowledge (Ernst, 2003), it has been actively used as a proxy for measuring technological convergence. Some research considers patents as a useful source to analyze the technology-driven convergence, demonstrating convergence between the pharmaceutical, the chemical, the nutrition and the cosmetics industries (Curran and Leker, 2009; Curran and Leker, 2011).

\section{Research Framework}

Figure 1: Overall process of this paper

\begin{tabular}{|c|c|c|}
\hline $\begin{array}{l}\text { Preliminary } \\
\text { work }\end{array}$ & Step 1. Define the target technological field & \\
\hline \multirow{2}{*}{$\begin{array}{l}\text { Technology } \\
\text { definition }\end{array}$} & $\begin{array}{l}\text { Step 2. Define the service technology } \\
\text { using business method patent ( } 705 \text { class) }\end{array}$ & \multirow{2}{*}{$\begin{array}{l}\text { USPTO } \\
\text { database }\end{array}$} \\
\hline & $\begin{array}{l}\text { Step 3. Define the manufacturing technology } \\
\text { using backward citation of service technology }\end{array}$ & \\
\hline \multirow{2}{*}{$\begin{array}{l}\text { Analysis of } \\
\text { convergence }\end{array}$} & $\begin{array}{l}\text { Step 4. Examine the technological convergence } \\
\text { of service \& manufacturing technology }\end{array}$ & \multirow{2}{*}{$\begin{array}{l}\text { Patent classification } \\
\text { analysis } \\
\text { dynamic } \\
\text { analysis }\end{array}$} \\
\hline & $\begin{array}{l}\text { Step 5. Analyze the dynamic change of convergence of } \\
\text { service \& manufacturing technology }\end{array}$ & \\
\hline
\end{tabular}


Define the target technological field: First, as a preliminary work, we define the target technological field to be investigated. Technological fields that show a high level of technological convergence between manufacturing technology and service technology are selected as objects of this study.

Define the service technology: The next step is to define the service technology. Since the service technology has rarely been discussed and has not been defined systematically (Lee et al., 2011), defining the service technology is an important but hard task. In this study, we employ business method (BM) patents, categorized as a 705 class in United States Patent and Trademark Office (USPTO) database, as a service technology. A BM patent is defined as a method of administering, managing, or operating an enterprise or organization (Koda, 2000; Han et al., 2011). These BM patents describe the real world business models of manufacturing and the service field in electronic environments, thus have been utilized as sources of information that can explain the business process or method thoroughly (Han et al., 2011). Even if a BM patent deals with the process and methods of general businesses, its main application area has been the service industry. For this reason, literature has discussed the characteristics of BM patent as related to the service. The 705 class which deals with BM patents is defined as "data processing: financial, business practice, management, or cost/price determination."

Define the manufacturing technology: After defining the service technology, we define the corresponding manufacturing technology associated with the service technology. Since the scope of manufacturing technology is too broad and thus extremely hard to be organized, we redefine the manufacturing technology here as "manufacturing technology associated with the service technology." For this reason, we collect the associated manufacturing technology using backward citation of identified service technology. In other words, patents cited in the service technology (which is collected in the previous step) are considered as candidates for manufacturing technology. Among those patents, patents except 705 class are finally considered as manufacturing technology.

Examine the technological convergence using patent classification: To investigate the technological convergence of manufacturing technology and service technology, we employ classification analysis. Since the USPC system is one of the most representative classification systems for technologies (Lee et al., 2011), we use USPC classification system. The USPCs are collected and analyzed for manufacturing technologies which are cited by service technologies. Since those technologies can be considered as converging technologies themselves, analysis of USPCs of those manufacturing technologies can provide a significant implication for technological convergence.

Analyze the dynamic changes of convergence: To investigate the dynamics of technological convergence, we conduct the dynamic analysis by changing the target period. For each period, service patents and associated manufacturing patents are analyzed.

\section{Case Study}

Data: To illustrate the working of our approach, we conducted a case study of technological convergence. We used the USPTO database (http://uspto.gov/) to identify the convergence pattern between manufacturing technology and service technology. To compare the convergence pattern between different industries, three industries where technological convergence actively happens are selected: banking industry, healthcare industry, and education industry. These industries, in common, show a great level of technological convergence as well as technological advances. Technology plays a key role to the prosperity of those industries by enhancing the performance of products or services, diversifying the delivery modes, and enlarging the communication channel. Especially, technological innovation in banking (Morone and Berg, 1993), healthcare (Schoolerman, 1993), and education (Hill, 1999) has led the prosperity of service industry. To investigate the convergence of each industry, the first step is to download the patents for both service and manufacturing. To investigate the convergence dynamics, data was collected for three-year period: 2000-2003. 2004-2006, and 2007-2009. Since the technological convergence between service technology and manufacturing technology is a recent phenomenon, we investigate the 10-year dynamics. Table 1 shows the number of service and manufacturing patents for each industry. 
Table 1: Number of patents for each industry

\begin{tabular}{lllllll}
\hline period & $\begin{array}{l}\text { Banking } \\
\text { Service } \\
\text { patents }\end{array}$ & $\begin{array}{l}\text { Mfg. } \\
\text { patents }\end{array}$ & $\begin{array}{l}\text { Sealthcare } \\
\text { patents }\end{array}$ & $\begin{array}{l}\text { Mfg. } \\
\text { patents }\end{array}$ & $\begin{array}{l}\text { Education } \\
\text { Service } \\
\text { patents }\end{array}$ & $\begin{array}{l}\text { Mfg. } \\
\text { patents }\end{array}$ \\
\hline $2001-2003$ & 42 & 348 & 47 & 439 & 14 & 179 \\
$2004-2006$ & 55 & 400 & 62 & 604 & 17 & 174 \\
$2007-2009$ & 100 & 672 & 123 & 878 & 28 & 216 \\
\hline
\end{tabular}

\section{Results}

Banking industry: To investigate the technological characteristics of those converging technologies, we investigate the class information of manufacturing technology. Since the service technology is defined as the patents categorized as 705 class, we investigate the class information of manufacturing technology only. Since those manufacturing technologies have contributed to develop the service technology in each convergence industry, we call it converging technologies. Table 2, 3, and 4 describes the result of top 10 classes for manufacturing technologies for each period.

Table 2: Top 10 classes for manufacturing technology for banking: 2001-2003

\begin{tabular}{lll}
\hline Class & Class description & count \\
\hline $235 / 379$ & Banking systems & 50 \\
$235 / 380$ & Credit or identification card systems & 16 \\
$709 / 202$ & Processing agent & 5 \\
$382 / 140$ & Reading micro data including an optical imager or reader & 5 \\
$713 / 176$ & Authentication by digital signature representation or digital watermark & 5 \\
$235 / 381$ & Systems controlled by data bearing records with vending & 4 \\
$435 / 005$ & Measuring or testing process involving enzymes or micro-organisms; & 3 \\
& composition or test strip therefore; processes of forming such composition or \\
$209 / 534$ & Sest strip involving virus or bacteriophage & 3 \\
$709 / 218$ & Remote data accessing using interconnected networks & 3 \\
$380 / 030$ & Particular algorithmic function encoding: public key & 3 \\
\hline
\end{tabular}

Table 3: Top 10 classes for manufacturing technology for banking: 2004-2006

\begin{tabular}{lll}
\hline Class & Class description & Count \\
\hline $235 / 379$ & Banking systems & 68 \\
$235 / 380$ & Credit or identification card systems & 12 \\
$209 / 534$ & Sorting paper money & 12 \\
$235 / 381$ & Systems controlled by data bearing records with vending & 8 \\
$380 / 030$ & Particular algorithmic function encoding : public key & 7 \\
$194 / 206$ & Control mechanism actuated by check, other than coin (e.g., slug, token, card, & 6 \\
$345 / 173$ & etc.), which is mutilated or retained by pliant currency & 3 \\
$713 / 157$ & Display peripheral interface input device : touch panel & 3 \\
$283 / 058$ & certificates & 3 \\
$709 / 229$ & Canking: checks & 3 \\
\hline
\end{tabular}


Table 4: Top 10 classes for manufacturing technology for banking: 2007-2009

\begin{tabular}{lll}
\hline Class & Class description & count \\
\hline $235 / 379$ & Banking systems & 117 \\
$235 / 380$ & Credit or identification card systems & 21 \\
$209 / 534$ & Sorting paper money & 10 \\
$235 / 381$ & Systems controlled by data bearing records with vending & 6 \\
$235 / 487$ & Records & 5 \\
$380 / 280$ & Key management control vector or tag & 4 \\
$235 / 383$ & Systems controlled by data bearing records: mechanized store & 4 \\
$380 / 277$ & Key management & 4 \\
$382 / 100$ & Applications & 4 \\
$382 / 115$ & Applications: personnel identification (e.g., biometrics) & 4 \\
$709 / 219$ & Remote data accessing: accessing a remote server & 4 \\
\hline
\end{tabular}

Since the target industry is a banking industry, technologies such as banking system technologies show great dominance. For all period, the most cited classes are the same: class of 235/379 (banking system) and 235/380 (credit or identification card system) are the dominant manufacturing technology to trigger the technological convergence between products and services in the banking industry. However, the dynamic differences between periods are also easily identified. Reading, processing, and bearing technologies are importantly considered at the early 2000 whereas the management and application technologies are highly cited in the late 2000 . For example, classes such as $380 / 280,235 / 383,380 / 277$, $382 / 100$, and $382 / 115$ are recently related to the service technology, emphasizing the management and application of those service technologies.

Healthcare industry: Table 5, 6, and 7 shows the top 10 classes for manufacturing technology for healthcare industry. Similar to the banking industry, the dominant class for technological convergence is same for all period: 600/300 (Diagnostic testing). However, details are quite different for each period. In the first period of 2000-2003, basic technologies for healthcare system play a key role in the technological convergence. Therefore, measurement system, detailed technologies for diagnostic testing, and data recording system are identified as the key converging technologies. However, in the period of 2004-2006, technologies for specific purposes are found, such as communication for handicapped, sensor controls, and printed matter methods (such as fingerprint) are considered as an important class for technological convergence. Finally, in the period of 2007-2009, more advanced technologies are identified. In this period, technologies related to the application and commercialization of the healthcare industry are commonly identified, such as remote data assessing, emergence communication, electric computers and digital processing system, credit card system, and personal identification system. Based on these technologies, we can assume that the basic development of the healthcare industry are finalized, thus technologies related to the actual commercialization are developed in this period.

Table 5: Top 10 classes for manufacturing technology for healthcare: 2001-2003

\begin{tabular}{lll}
\hline Class & Class description & count \\
\hline $600 / 300$ & Diagnostic testing & 39 \\
$433 / 024$ & Method of positioning or aligning teeth & 9 \\
$600 / 301$ & $\begin{array}{l}\text { Diagnostic testing via monitoring a plurality of physiological data, e.g., pulse and } \\
\text { blood pressure }\end{array}$ & 8 \\
& Measurement system: due time monitoring (e.g., medication clock, maintenance & 5 \\
$702 / 177$ & interval) & 5 \\
& Time measuring systems or devices combined with disparate device & 4 \\
$368 / 010$ & Feeding device: having electronic identification and feed control & 4 \\
$119 / 051.02$ & & 4 \\
$706 / 045$ & knowledge processing system & 3 \\
$434 / 236$ & Diagnostic testing: simultaneously detecting cardiovascular condition and diverse & 4 \\
$600 / 513$ & body condition & 3 \\
& Diagnology & \\
$235 / 375$ & characteristic & 3 \\
\hline
\end{tabular}


Table 6: Top 10 classes for manufacturing technology for healthcare: 2004-2006

\begin{tabular}{lll}
\hline Class & Class description & count \\
\hline $600 / 300$ & Diagnostic testing & 48 \\
$600 / 301$ & $\begin{array}{l}\text { Diagnostic testing via monitoring a plurality of physiological data, e.g., pulse and } \\
\text { blood pressure }\end{array}$ & 12 \\
& Method of positioning or aligning teeth & 10 \\
$433 / 024$ & Systems controlled by data bearing records & 7 \\
$235 / 375$ & Communication aids for the handicapped & 6 \\
$434 / 112$ & Means for introducing or removing material from body for therapeutic & 6 \\
$604 / 067$ & purposes: sensor controls pump, motor, or pressure driven means & 4 \\
$604 / 066$ & Means for introducing or removing material from body for therapeutic & 4 \\
$283 / 067$ & purposes: sensor responsive to body condition & 4 \\
$600 / 483$ & $\begin{array}{l}\text { Diagnostic testing: simultaneously detecting cardiovascular condition and } \\
\text { diverse body condition }\end{array}$ & 4 \\
$434 / 262$ & $\begin{array}{l}\text { Anatomy, physiology, therapeutic treatment, or surgery relating to human being } \\
235 / 380\end{array}$ & Credit or identification card systems \\
$709 / 202$ & Distributed data processing: processing agent & 3 \\
\hline
\end{tabular}

Table 7: Top 10 classes for manufacturing technology for healthcare: 2007-2009

\begin{tabular}{lll}
\hline Class & Class description & count \\
\hline $600 / 300$ & Diagnostic testing & 66 \\
$600 / 301$ & $\begin{array}{l}\text { Diagnostic testing via monitoring a plurality of physiological data, e.g., pulse and } \\
\text { blood pressure }\end{array}$ & 12 \\
& Systems controlled by data bearing records & 11 \\
$235 / 375$ & Remote data accessing & 7 \\
$709 / 217$ & Emergency or alarm communications: central office responsive to emergency & 6 \\
$379 / 045$ & call or alarm (e.g., "911", operator position display) & 6 \\
& Processes with recorder, register, indicator, signal or exhibitor & 5 \\
$721 / 002$ & Electrical computers and digital processing systems: multicomputer data & 5 \\
$709 / 200$ & transferring: miscellaneous & 5 \\
$735 / 380$ & Credit or identification card systems & 4 \\
$382 / 115$ & Linguistics: natural language & 4 \\
$709 / 203$ & Personnel identification (e.g., biometrics) & 4 \\
$706 / 045$ & Knowledge processing system & 4 \\
$709 / 229$ & Network resources access controlling & 4 \\
$600 / 523$ & Diagnostic testing: signal display or recording & 5 \\
\hline
\end{tabular}

Education industry: Finally, table 8, 9, and 10 shows the top 10 classes for manufacturing technology for education industry. Similar to the previous cases, the dominant class for technological convergence is almost same for all period: 434/350 (Response of plural examinees communicated to monitor or recorder by electrical signals), except the final period of 2007-2009. At the early period (2001-2003), basic technologies such as data processing, computer logic, and related means for data processing are considered as important manufacturing technologies for the education industry. In the middle period (2004-2006), technologies related to the advanced features are developed, such as computer graphics processing and operator interface for plural users or sites (e.g., network). Basic technologies for education are already developed for the first two periods (2001-2003 and 2004-2006), thus the application and advanced technologies are developed in the final period (2007-2009). For example, classes such as computer network monitoring and management, remote data accessing, and network resources controlling emerge as important classes for technological convergence. Especially, technologies with network show a great improvement, which reflects the practical circumstance of education industry. With the rise of mobile device, application of network management or remote control is considered as a key factor for education. 
Table 8: Top 10 classes for manufacturing technology for education: 2001-2003

\begin{tabular}{llc}
\hline Class & Class description & count \\
\hline $434 / 350$ & $\begin{array}{l}\text { Response of plural examinees communicated to monitor or recorder by } \\
\text { electrical signals }\end{array}$ & 10 \\
$600 / 300$ & Diagnostic testing & 6 \\
$434 / 323$ & Cathode ray screen display included in examining means & 5 \\
$434 / 322$ & Question or problem eliciting response & 4 \\
$463 / 017$ & Including means for processing electronic data: lot match or lot combination & 3 \\
& (e.g., roulette, lottery, etc.) & 3 \\
$434 / 236$ & Psychology & 3 \\
$434 / 258$ & Physical education: developing or testing coordination & 3 \\
$434 / 118$ & Computer logic, operation, or programming instruction & 3 \\
$434 / 362$ & Electrical means for recording examinee's response & 3 \\
$235 / 380$ & Credit or identification card systems & \\
\hline
\end{tabular}

Table 9: Top 10 classes for manufacturing technology for education: 2004-2006

\begin{tabular}{lll}
\hline Class & Class description & count \\
\hline $434 / 350$ & $\begin{array}{l}\text { Response of plural examinees communicated to monitor or recorder by } \\
\text { electrical signals }\end{array}$ & 10 \\
$434 / 322$ & Question or problem eliciting response & 7 \\
$600 / 300$ & Diagnostic testing & 6 \\
$709 / 217$ & Remote data accessing & 3 \\
$434 / 262$ & Anatomy, physiology, therapeutic treatment, or surgery relating to human being & 3 \\
$706 / 045$ & Knowledge processing system & 3 \\
$514 / 725$ & Vitamin a compound or derivative & 3 \\
$706 / 059$ & Knowledge processing system: creation or modification & 2 \\
$345 / 440$ & Computer graphics processing: graph generating & 2 \\
$434 / 118$ & Computer logic, operation, or programming instruction & 2 \\
$715 / 733$ & Operator interface: for plural users or sites (e.g., network) & 2 \\
$434 / 353$ & Grading of response form & 2 \\
$706 / 023$ & Neural network: control & 2 \\
$434 / 362$ & Electrical means for recording examinee's response & 2 \\
$709 / 218$ & Remote data accessing using interconnected networks & 2 \\
$273 / 243$ & Chance device controls amount or direction of movement of piece & 2 \\
$715 / 205$ & Presentation processing of document: hypermedia & 2 \\
\hline
\end{tabular}

Table 10: Top 10 classes for manufacturing technology for education: 2007-2009

\begin{tabular}{lll}
\hline Class & Class description & count \\
\hline $434 / 322$ & Question or problem eliciting response & 6 \\
$709 / 224$ & Computer network monitoring & 4 \\
$709 / 223$ & Computer network managing & 3 \\
$600 / 300$ & Diagnostic testing & 3 \\
$709 / 217$ & Remote data accessing & 3 \\
$434 / 350$ & Response of plural examinees communicated to monitor or recorder by & 3 \\
& electrical signals & 3 \\
$709 / 229$ & Network resources access controlling & 2 \\
$709 / 218$ & Remote data accessing using interconnected networks & 2 \\
$434 / 107$ & Business or economics & 2 \\
$715 / 735$ & Operator interface: configuration & 2 \\
$700 / 291$ & Energy consumption or demand prediction or estimation & 2 \\
$715 / 736$ & Network managing or monitoring status & 2 \\
$455 / 446$ & Radiotelephone system: including cell planning or layout & 2 \\
$703 / 011$ & Simulating nonelectrical device or system: biological or biochemical & 2 \\
$434 / 236$ & Psychology & \\
\hline
\end{tabular}




\section{Conclusion}

This study aims to investigate the technological convergence between manufacturing technology and service technology using patent classification analysis. For this purpose, we first define the service technology and corresponding manufacturing technology. Then, we employ patent classification analysis to investigate the technological convergence between manufacturing and service technologies. This paper contributes to the fields in twofold. First, the process of defining service technology and corresponding manufacturing technology is suggested using citation analysis. This can provide a fruitful chance for further research to investigate the relationship between manufacturing technologies and service technologies. Second, we suggest a method to investigate the technological convergence using classification analysis. Based on the definition of manufacturing technology associated with the service technology, we regard the class information as a proxy for investigating the technological convergence. Despite the contribution, however, this paper is still subject to some limitations. First, the definition of service technology requires further in-depth consideration. Even if BM patents are frequently applied to the service sector, it might be hard to consider all BM patents as service patents. Second, currently, we employ patent classification analysis as a means to investigate the technological convergence, since the target patents are derived based on the consideration of technological convergence process. However, more advanced techniques can be employed such as co-classification analysis.

Acknowledgement: This work was supported by the National Research Foundation of Korea Grant funded by the Korean Government (NRF-2011-32A-B00050).

\section{References}

Auernhammer, K. \& Stabe, M. (2002). Integrated development of products and services, In: Mařík, V., Camarinha-Matos, L., and Afsarmanesh, H. (Eds), Knowledge and Technology Integration in Production and Services: Balancing Knowledge and Technology in Product and Service Life Cycle, Springer

Blackman, C. R. (1998). Convergence between telecommunications and other media: how would regulation adapt? Telecommunications Policy, 22(3), 167-170.

Bitner, M. J. (2001). Service and technology: opportunities and paradoxes. Managing Service Quality, 11(6), 375-379.

Bores, C., Saurina, C. \& Torres, R. (2003). Technological convergence: a strategic perspective, Technovation, 23(1), 1-13.

Curran, C. S. \& Leker, J. (2009). Forecasting Industry Convergence: Developing Reliable Measures on the Basis of STN AnaVist, The Proceedings of The XX ISPIM Conference 2009, Vienna

Curran, C. S. \& Leker, J. (2011). Patent Indicators for Monitoring Convergence - Examples from NFF and ICT. Technological Forecasting and Social Change, 78(2), 256-273.

Ernst, H. (2003). Patent Information for Strategic Technology Management. World Patent Information, 25(3), 233-242.

Gambardella, A. \& Torrisi, S. (1998). Does technological convergence imply convergence in markets? Evidence from the electronics industry. Research Policy, 27(5), 445-463.

Geum, Y., Lee, S., Kang, D. \& Park, Y. (2011). The customization framework for road mapping productservice integration. Service Business, 5(3), 213-236.

Geum, Y., Lee, S., Kim, C. \& Kim, M. (2012). Technological Convergence of IT and BT: Evidence from Patent Analysis. ETRI Journal, 34(3), 439-449.

Grilliches, Z. (1990). Patent statistics as economic indicators: A survey. Journal of Economic Literature, 28(4), 1661-1707.

Hacklin, F. (2008). Management of Convergence in Innovation - Strategies and Capabilities for Value Creation Beyond Blurring Industry Boundaries, Physica-Verlag, Heidelberg

Hacklin, F., Marxt, C. \& Fahrni, F. (2009). Coevolutionary Cycles of Convergence: An Extrapolation from the ICT Industry. Technological Forecasting \& Social Change, 76(6), 723-736.

Han, W., Lee, S. \& Park, Y. (2011). IT-based evolution of service business model: Case of education service, 2011 3rd International Conference on Information and Financial Engineering, Shanghai, China

Hill. M.W. (1999). The Impact of Information Technology on Society. London: Bowker Saur

Karvonen, M. \& Kässi, T. (2011). Patent Citation Analysis as a Tool for Analyzing Industry Convergence, The Proceedings of PICMET (Technology Management in the Energy Smart World), Portland

Kang, H. (2006). Technology management in services: knowledge-based vs. knowledge-embedded 
services. Strategic Change, 15(2), 67-74.

Koda, H. (2000). Business models patent. Tokyo: Nikel Kogyo Shinbunsha

Lee, H., Kim, C., Cho, H. \& Park, Y. (2009). An ANP-based technology network for identification of core technologies: A case of telecommunication technologies. Expert Systems with Applications, 36, 894-908

Lee, S., Olson, D. L. \& Trimi, S. (2010). The Impact of Convergence on Organizational Innovation. Organizational Dynamics, 39(3), 218-225.

Lee, S., Geum, Y., Kim, M. S. \& Kim, J. (2011). How technologies can facilitate service innovation? The Proceedings of the 4th ISPIM Innovation Symposium, Wellington, New Zealand

Martinez, V., Bastl, M., Kingston, J. \& Evan, S. (2010). Challenges in transforming manufacturing organizations into product-service providers. Journal of Manufacturing Technology Management, 21, 449-469.

Morone, J. \& Berg, D. (1993). Management of technology in the service sector: Practices in the banking industry. Journal of High Technology Management Research, 4(1), 123-137.

Narin, F., Noma, E. \& Perry, R. (1987). Patents as indicators of corporate technological strength. Research Policy, 16(2/4), 143-155.

Quinn, J. B. Baruch, J. J. \& Paquette, P. C. (1988). Exploiting the manufacturing service interface. Sloan Management Review, 29(4), 45-56.

Quinn, J. B. \& Paquette, P. C. (1990). Technology in services: Creating organizational revolutions. Sloan Management Review, 31(2), 67-78.

Rosenberg, N. (1963). Technological Change in the Machine Tool Industry, 1840-1910. The Journal of Economic History, 23(4), 414-446.

Schoolerman, S. (1993). Service, technology positions Pyxis for success. Health Industry Today, 56(6), 1617.

Stehrer, R. \& Worz, J. (2003). Technological Convergence and Trade Patterns. Review of World Economics, 139(2), 191-219.

Tijssen, R. J. W. (1992). A quantitative assessment of interdisciplinary structures in science and technology: Co-classification analysis of energy research. Research Policy, 21(1) 27-44.

Wartburg, I., Teichert, T. \& Rost, K. (2005). Inventive progress measured by multi-stage patent citation analysis. Research Policy, 34(10), 1591-1607. 